to Stephen Hawking's $A$ brief history of time, which is also a best seller and which attempts to do for cosmology what Dawkins does for natural selection. For anyone with an interest in theoretical biology written in an interesting and seductive manner this is a must.

\section{Alan Emery}

Biochemical Genetics: A Laboratory Manual. Emmanuel Shapira, Miriam G Blitzer, James Miller, Diane $\mathrm{K}$ Africk. (Pp 145; £19.50.) New York, Oxford: Oxford University Press. 1989.

This book makes no pretence of being anything more than a bench book on biochemical genetics, as illustrated by its contents and general quality of presentation. Part I deals with enzyme assays, describing general procedures and buffers, and methods for specific enzymes using fluorimetric, spectrophotometric, and radioisotope techniques. It should be noted that all but two of the methods are for lysosomal enzymes, indicating a distinct bias in the contents of this section, which presumably reflects the specialised interests of the authors.

Part II is on diagnostic tests for metabolic disorders, specimen collection, and handling. There are sections on urine spot tests, thin layer chromatography of a number of types of metabolite, quantitative amino acid analysis, organic acid analysis by gas chromatography, and free and esterified carnitine assays. An appendix tabulates the clinical presentation of a range of disorders, including those of lysosomal storage, the urea cycle, and amino acid and organic acid metabolism.

There are obvious reservations about a book of this nature. One is that it is a simple recipe book of methods in use in the authors' laboratory and there is no critical appraisal of the techniques. Moreover, some of these methods, that for quantitative amino acids for example, are only valid for one particular type of analyser, and the information is of very limited value for a laboratory with alternative instrumentation. A second is that it might encourage a belief that methods like chromatography of amino acids and organic acids, and interpretation of the results, are straightforward matters which are learned easily. Recent experience of quality control of urine amino acids in the UK has shown that this, and similar procedures, should not be undertaken lightly.

In conclusion, it is difficult to imagine that this book will have a wide appeal. Most established workers in this field would want to search widely before introducing a new technique. In general, it is accepted that biochemical genetics is best concentrated in centres where expertise already exists and newcomers, who might be attracted by this book, should be relatively few in number.

JoHN HoLton

Human Gene Mapping 10. 10th International Workshop on Human Gene Mapping. (Pp 1147; £122·10.) Basel: Karger. 1989.

The First International Human Gene Mapping Workshop (HGM1) was held at Yale University in 1973 and the proceedings appeared in a slim monograph listing 31 confirmed autosomal assignments and offering a tentative map of 13 loci on the $\mathrm{X}$ chromosome. Sixteen years and a revolution in molecular biology later, the Tenth Workshop returned to Yale and has generated a tome to dwarf any telephone directory containing information on some 5000 mapped genes and DNA markers. This is essential reference material for the increasing numbers of scientists working on the human genome, as well as for those providing a service for patients with genetic disorders.

The information is presented in various ways to make it accessible to the reader. Committees assigned to individual chromosomes have produced reports summarising the data and highlighting additions and changes. The committee on clinical disorders and chromosome deletion syndromes has collated the information in a format which clinicians will find useful. Almost a third of the publication is taken up with the catalogues of 3400 DNA segments and 945 cloned genes. Abstracts of workshop presentations constitute another large section. One bar to communication and source of irritation is the exclusive use of $D$ numbers throughout the text, necessitating repeated reference to the index of DNA segments. Since most researchers use probe names in their everyday work, it would be helpful if these could also be given, perhaps in brackets.

Past workshops have managed to keep abreast of the increasing amounts of data on DNA markers and physical mapping, but presentation of data on genetic distances has been haphazard and incomplete. For a DNA marker of interest, one could readily find details of the probe, vector, and polymorphism, probably some indication of the cytogenetic localisation, and perhaps some ordering information, but seldom details of the genetic distance from nearby markers or disease loci. To meet this need, HGM10 includes summary scores from Bronya Keats's database of pairwise lod scores taken from published reports and workshop submissions. These scores, together with information on order derived from multipoint linkage maps and physical mapping data, have been used to construct genetic maps for each chromosome. This commitment to the compilation of linkage data is most welcome and would be all the more useful if the source of the primary data could also be listed.

HGM10 was made possible by an online database which allowed entry and modification of data by the 26 workshop committees and facilitated publication of the final report in only three months, a remarkable achievement. More sophisticated computerisation will be needed as the volume of information increases and there may well be changes in the way the data are contributed and validated by the scientific community. Certainly the format by which the compiled data are made available will have to change as the remaining $97 \%$ of the genome is mapped, otherwise we shall all need to reinforce our book shelves.

JOHN R W YATES

Genetic Variants and Strains of the Laboratory Mouse. 2nd ed. Ed Mary F Lyon, Anthony G Searle. (Pp 876; £90.00.) Oxford: Oxford University Press. 1989.

A brief period in the late sixties, studying as an undergraduate in Hans Gruneberg's department, taught me that mouse geneticists are different 